\title{
Response Rates in a Nursing Intervention Longitudinal Study on Vulnerable Elderly Patients
}

\author{
Steve Strupeit, $\mathbf{P h D}^{1, *}$, Arne Buss, BA, $\mathbf{M S c N}^{2}$ \\ Professor, Department 11, Applied Social Sciences, University of Applied Sciences Munich, Am Stadtpark 20, \\ 81243 München, Germany \\ Research Associate, Department 11, Applied Social Sciences, University of Applied Sciences Munich, Am \\ Stadtpark 20, 81243 München, Germany.
}

*Corresponding Author: Steve Strupeit, Professor, Department 11, Applied Social Sciences, University of Applied Sciences Munich, Am Stadtpark 20, 81243 München, Germany. Email: strupeit @ hm.edu.

\begin{abstract}
Introduction: In the present study we sought to calculate the response rate in an experimental trial on a vulnerable elderly population and to examine reasons for nonparticipation. Additionally we aimed to determine the response rate of a later subsequent study were the same cohort was re-recruited.

Materials and Methods: The number of all eligible patients was collected to determine the sample size. Then the response rate was calculated by dividing the number of eligible patients by the number of participants. Analysis of reasons for refusal was conducted descriptively by checking patient records.

Results and Discussion: In the first study the overall response rate was $25.2 \%$ compared to $52 \%$ in the subsequent study was. There were several reasons for refusal, such as feeling over challenged or interference with privacy. The findings of this study revealed that when recruiting participants for long-term intervention studies vulnerable elderly populations, especially women, tend to show low response rates, in particular for the intervention group.
\end{abstract}

Conclusions: Researchers in this field should be aware of this issue and the risk of a nonresponse bias. Rerecruiting may increase response rate.

Keywords: Response rate; Recruitment; elderly; Nursing intervention; Longitudinal study

\section{INTRODUCTION}

Recruitment of study participants can carry risks that may threat external validity. One bias that can occur during the recruitment is the nonresponse bias. A nonresponse bias (or response bias) is a bias that can result when a non-random subset of people invited to participate in a study fail to participate [1]. A nonresponse bias is related to the response rate. The response rate is the number of people participating in a study relative to the number of people sampled [1]. The higher the response rate the lower is the risk for a nonresponse bias. Polit $\&$ Beck [1] state that "a response rate greater than $65 \%$ is probably sufficient for most purposes, but lower response rates are the norm."

In several studies the authors sought to calculate the response rates and identify characteristics separating participants from nonparticipants or reasons for refusal. Lahmann et al. [2] in their prevalence study calculated response rates of $80.2 \%$ (2002) and $76.3 \%$ (2003) respectively. Puts et al. [3] in a study on cancer patients determined a response rate of $72 \%$.

There were numerous reasons for refusal, such as lack of acceptance, a lack of attendence [2], fear, lack of time [3], or feeling too ill or too healthy $[3,4]$.

Experimental studies examining the effects of educational interventions on quality of life or functional status in elderly people show response rates of $30.9 \%$ [5], 59.6\% [6], 62.6\% [7], $77.1 \%$ [8], or 99.6\% [9]. However in some studies it is not comprehensible why the authors differentiate between eligible patients and patients fulfilling inclusion criteria. Thus the sample sizes are not clear. If the authors reported reasons for nonparticipation these were refusal or decline to participate $[5,6,7]$ or lack of consent [8]. 
In the present study we sought to calculate the response rate in an experimental trial on a vulnerable elderly population and to examine reasons for nonparticipation.

Additionally we aimed to determine the response rate of a later subsequent study were the same cohort was re-recruited in order to compare both response rate.

\section{Materials AND MethodS}

\subsection{The Study Project}

The Longitudinal Urban Cohort Ageing Study (LUCAS) is a cohort study of communitydwelling seniors complemented by specific studies of geriatric patients or diseases (Dapp et al. 2012). Within the LUCAS-study seven subprojects are being conducted, approaching specific populations and research fields and questions three of which have contributed to this study.

The study Subproject "Immobility in old patients - trans-sectional care aspects (FALLEN): Nurse-driven counseling (reinforcement)" aimed at developing and testing the effectiveness of a concept to maintain and facilitate mobility in aged and old-aged multimorbid people in and after hospital discharge. The Intervention comprised nursedelivered guidance, consultation, and training. The intervention was provided during clinical stay as well as post discharge and comprised inpatient consultation, home visitations and phone calls. Effectiveness of the intervention was evaluated by using a quasi-experimental study design (study 1). The main outcomes measured were mobility (functional status) and quality of life[10].

For a second project phase, the intervention was evaluated and adapted. It was then carried out outpatient and its effectiveness on functional status and quality of life was tested by using a randomized controlled trial design (study 2).

\subsection{Ethical Approval}

The study protocol was approved by the Ethics Commission of the Medical Association of Hamburg (PV2972).

\subsection{Participants and Recruitment}

The participants were recruited from the Albertinen- Haus geriatric rehabilitation facility in Hamburg, Germany. The inclusion criteria

Table1. Baseline characteristics according to group were an established diagnosis of functional mobility impairment of the musculoskeletal system or stroke (ICD-10: S00-T98 [except T36-87], T89, T88, T90-T95, T98, M00-M99, I61, I63, or I66), age older than 60 years, no spatial or temporal orientation deficits, no function-impairing cognitive impairments, the ability to communicate (motorically, cognitively, and psychologically), the ability to speak German, residence in Greater Hamburg (home or nursing home), and the provision of written informed consent. The exclusion criteria were a score of less than 25 points on the MMSE and discharge within the first week of the study. Additionally, individuals with a disease expected to lead to death during the study period were excluded from the study. A physician was consulted to identify these individuals. This criterion typically affected patients receiving palliative care. The average length of hospitalization among these patients was three weeks.

Two study nurses, two research associates, and student assistants recruited the participants. In a first phase the study nurses daily collected data from newly admitted patients and checked it for eligibility. Then the study nurses, supervised by the research associates, decided which patient finally was eligible to participate in the study. The eligible patients then were informed about participation. When written consent was given by the patients they were included in the study and baseline data were collected. Reasons for refusal and events leading to nonparticipation were standardized recorded.

\subsection{Data Analysis}

Data were analyzed by using descriptive methods. Data from patient records were digitalized and proportions of participants and nonparticipants were calculated. Analysis of reasons for refusal was conducted descriptively by checking patient records.

\section{RESUlTS AND DisCUSSION}

\subsection{Participants Characteristics}

Table 1 shows the characteristics of the study participants according to group allocation. There was a higher proportion of male participants in the intervention group and participants in the control group had a better overall quality of life.

\begin{tabular}{|l|l|l|l|}
\hline & Intervention group & Control group & Sig. (if applicable) $\left(\boldsymbol{p}^{1}\right)$ \\
\hline $\mathbf{n}^{2}(\boldsymbol{\%})$ & $39(31.8)$ & $85(68.2)$ & \\
\hline Mean age, $\mathbf{y}\left(\mathbf{S D}^{3}\right)$ & $83.72(6.87)$ & $83.44(8.71)$ & .052 \\
\hline Sex, $\mathbf{n}(\boldsymbol{\%})$ & & & .000 \\
\hline
\end{tabular}


Response Rates in a Nursing Intervention Longitudinal Study on Vulnerable Elderly Patients

\begin{tabular}{|c|c|c|c|}
\hline Male & $34(87.2)$ & $28(32.9)$ & \\
\hline Female & $5(12.8)$ & $57(67.1)$ & \\
\hline Birthplace, n (\%) & & & .663 \\
\hline Germany & $36(94.7)$ & $75(92.6)$ & \\
\hline Other & $2(5.3)$ & $6(7.4)$ & \\
\hline Marital status, n (\%) & & & .139 \\
\hline Married & $9(23.1)$ & $29(35.8)$ & \\
\hline Single & $2(5.1)$ & $8(9.9)$ & \\
\hline Divorced & $7(17.9)$ & $6(7.4)$ & \\
\hline Widowed & $20(51.3)$ & $38(46.9)$ & \\
\hline Education, n (\%) & & & .322 \\
\hline $\begin{array}{l}\text { Secondary school Level I (up to 10th } \\
\text { grade) }\end{array}$ & $23(59.0)$ & $57(70.3)$ & \\
\hline $\begin{array}{l}\text { Secondary school Level II (beyond } \\
\text { 10th grade) }\end{array}$ & $14(35.9)$ & $20(24.8)$ & \\
\hline Other & $2(5.1)$ & $4(4.9)$ & \\
\hline $\begin{array}{l}\text { Professional education } \\
\text { (Berufsabschluss), n }(\%)\end{array}$ & & & .852 \\
\hline Vocational training & $23(60.5)$ & $50(61.7)$ & \\
\hline University degree & $6(15.8)$ & $12(14.8)$ & \\
\hline Other & $1(2.6)$ & $3(3.7)$ & \\
\hline No professional education & $8(21.1)$ & $16(19.8)$ & \\
\hline Barthel Index & $63.97(21.71)$ & $68.37(21.95)$ & .951 \\
\hline \multicolumn{4}{|l|}{ WHOQOL-BREF $^{4}$} \\
\hline Overall & $36.86(19.65)$ & $44.33(24.15)$ & .018 \\
\hline Physical & $48.35(15.61)$ & $47.90(17.35)$ & .725 \\
\hline Psychological & $57.56(18.69)$ & $58.73(18.32)$ & .650 \\
\hline Social & $75.21(18.16)$ & $70.83(19.88)$ & .306 \\
\hline Environmental & $62.15(12.66)$ & $65.20(13.90)$ & .836 \\
\hline Self-efficacy & $25.97(5.13)$ & $26.10(6.25)$ & .121 \\
\hline MMSE $^{5}$ & $27.97(2.15)$ & $27.98(1.60)$ & .640 \\
\hline MNA $^{6}$ & $22.76(3.75)$ & $21.78(3.37)$ & .716 \\
\hline
\end{tabular}

${ }^{1}$ p-value; ${ }^{2}$ Number; ${ }^{3}$ Standard Deviation; ${ }^{4}$ World Health Organization Quality of Life-BREF; ${ }^{5}$ Mini-Mental State Examination; ${ }^{6}$ Mini Nutritional Assessment

\subsection{Response Rates}

For the first study, overall 492 patients fulfilled the eligibility criteria. Of these 124 patients gave consent to participate in the study. Thus the overall response rate (for both groups) was $25.2 \%$. Male patients showed to be considerably more willing to participate in the study (48.8\%), compared to female patients $(17.0 \%)$. The response rate for the intervention group recruitment was lower (13.5\%) compared to the control group $(42.1 \%)$. Whereas about half of the men (51.5\%) were more willing to participate in the intervention group only few women gave consent for participation (2.2\%). For the control group response rates between male and female patients were comparable (see Table 2).

For the second Phase (study 2), 125 individuals from the original participants were re-recruited. Of these 65 individuals gave consent to participate in the study, indicating a response rate of $52 \%$ (see Table 3 ).

Table2. Response rates study 1

\begin{tabular}{|l|c|c|c|c|c|c|c|c|c|}
\hline & \multicolumn{3}{|c|}{ Overall } & \multicolumn{2}{c|}{ Intervention Group } & \multicolumn{3}{c|}{ Control Group } \\
\hline & Overall & Women & Men & Overall & Women & Men & Overall & Women $^{1}$ & Men \\
\hline $\begin{array}{l}\text { Fulfilled } \\
\text { inclusion } \\
\text { criteria (n) }\end{array}$ & 492 & 365 & 127 & 290 & 224 & 66 & 202 & 141 & 61 \\
\hline $\begin{array}{l}\text { Participated in } \\
\text { the study (n) }\end{array}$ & 124 & 62 & 62 & 39 & 5 & 34 & 85 & 57 & 28 \\
\hline $\begin{array}{l}\text { Response rate } \\
(\%)\end{array}$ & $25.2 \%$ & $17.0 \%$ & $48.8 \%$ & $13.5 \%$ & $2.2 \%$ & $51.5 \%$ & $42.1 \%$ & $40.4 \%$ & $45.9 \%$ \\
\hline
\end{tabular}

${ }^{1}$ Number 
Table3. Response rates study 2

\begin{tabular}{|l|c|}
\hline & Overall \\
\hline Fulfilled inclusion criteria $\left(\mathbf{n}^{\mathrm{I}}\right)$ & 125 \\
\hline Participated in the study (n) & 65 \\
\hline Response rate (\%) & $52 \%$ \\
\hline
\end{tabular}

${ }^{1}$ Number

\subsection{Reasons for Nonparticipation/Refusal}

Reasons for refusal were recorded in the intervention group recruitment. Overall there were numerous reasons. The patients stated that they feel over challenged $(n=5)$, do not want to receive home visits $(n=4)$, do not want to be under obligation $(\mathrm{n}=4)$, do not want to reveal personal data $(\mathrm{n}=3)$, are not interested in the intervention $(n=4)$, feel too young $(n=2)$, or refused to participate after talking to their relatives $(n=2)$.

During the recruitment for the second phase the nonparticipants stated that their relatives do not agree with a participation $(n=3)$, that they are not interested $(\mathrm{n}=5)$, or that they do not want to receive home visits from strangers $(\mathrm{n}=1)$. Thirteen individuals died and the other nonparticipants either did not state any reasons for refusal or could not be contacted.

The aim of the study was to calculate the response rate and to examine reasons for nonparticipation.

The overall response rate (intervention and control group) in the present study was $25.2 \%$. compared to other studies examining a similar population (Desroisiers et al. 2007, Jerant et al. 2009, Andersen et al. 2002, Harrington et al. 2010) our response rate was considerably low. Bakas et al. (2009) showed a comparable response rate in their study. A low response rate may increase the risk of a nonresponse bias. Thus a non-random subset of our population may have been excluded in our study. As we examined a vulnerable population this may have led to such a low proportion of participants. Our sample consisted of elderly people who just have experienced a severe impact (i.e. stroke or fracture) leading to a decrease in their functional status. This may have influenced their decision not to participate in any study. To address this issue in further studies on this population it could beneficial to perform recruitment when patients already received rehabilitation. In this study we performed recruitment at admission. Our data show that functional status of the participants was lowest at admission and increased afterwards [10]. Patients may be more willing to participate when their functional status has improved. Additionally, the relation between the recruiters and the patients could have influenced the patients' decision because the study nurses who carried out the recruitment were not part of the clinic staff. It could have been more beneficial if the clinicians or other staff members had performed recruitment. Moreover the patients had to do deal with paperwork if they wished to participate because participants had to sign five documents in order to give consent. As especially female patients showed a low response rate (overall and in the control group recruitment) this seems to apply to women in particular. Moreover the lowest response rate was found for the intervention group recruitment. About half of the male patients and more than $95 \%$ of the female patients refused to participate in the intervention group. This may have been caused by the character of the intervention which required active participation and availability for a longer time. Additionally the intervention comprised personal contact in terms of home visits phone calls which could have been perceived as an interference with privacy. This stays in line with the nonparticipants reasons for refusal. Some of them stated that they feel over challenged, do not want to receive home visits, or do not want to reveal personal data. However reasons for nonparticipation could be collected from only few patients. Qualitative interviews were planned to evaluate reasons for nonparticipation but could not be performed because the ethics commission did not approve application. To address concern over interference with privacy researchers could phone refusers by using interview guides [11].

Additionally we aimed to determine the response rate of a later subsequent study were the same cohort was re-recruited in order to compare both response rate.

When the same participants from the first phase were recruited for the second phase, the response rate showed to be about twice as high as the response rate in the first phase. Thus it can be concluded that individuals from the population examined who already took part in a similar study, are more likely to give consent to participate. These individuals may have been 
more aware of what they are confronted with. Additionally it can be assumed that they are more willing to participate because they already know the study nurses and therefore build confidence.

\section{Conclusions}

To address issues of low response rates in elderly vulnerable populations in studies with comprehensive long-term interventions, researchers should consider possible reasons for nonparticipation. Vulnerable elderly populations, especially women, often do not want to participate in studies, in particular in intervention groups. As low response rates cannot be avoided all researchers should be aware of the risk of a non response bias. When re-recruiting former study participants for a subsequent study this may increase the response rate.

\section{ACKNOWLEDGEMENTS}

The work was funded by the German Federal Ministry of Education and Science (BMBF) (grant number 01ET1002C) - network spokesman Prof. Dr. Wolfgang von Renteln Kruse.

\section{REFERENCES}

[1] Polit DF, Beck CT. Nursing research: generating and assessing evidence for nursing practice. 8th ed. Philadelphia: Wolters Kluwer, Lippincott Williams \& Wilkins; 2008.

[2] Lahmann N, Halfens RJ, Dassen T. Effect of non-response bias in pressure ulcer prevalence studies. J Adv Nurs. 2006; 55(2):230-236. doi: 10.1111/j.1365-2648.2006.03906.x

[3] Puts MT, Monette J, Girre V, Wolfson C, Monette M, Batist G, Bergman H. Participation of older newly-diagnosed cancer patients in an observational prospective pilot study: an example of recruitment and retention. BMC Cancer 2009; 10(9):277. doi: 10.1186/14712407-9-277
[4] Vass M, Avlund K, Hendriksen C. Randomized intervention trial on preventive home visits to older people: Baseline and follow-up characteristics of participants and nonparticipants. Scand J of Public Health 2007; 35:410-417.

[5] Bakas T, Farran CJ, Austin JK, Given BA, Johnson EA, Williams LS. Stroke caregiver outcomes from the Telephone Assessment and Skill-Building Kit (TASK). Top Stroke Rehabil 2009; 16(2):105-121. doi: 10.1310/tsr1602-105

[6] Desroisiers J, Noreau L, Rochette A, Carbonneau H, Fontaine L, Viscogliosi C, Bravo G. Effect of a home leisure education program after stroke: A randomized controlled trial. ArchPhysMedRehabil2007; 88:10951100. doi:10.1016/j.apmr.2007.06.017

[7] Jerant A, Moore-Hill M, Franks P. Homebased, peer-led chronic illness self-management training: findings from a 1-year randomized controlled trial. Ann Fam Med. 2009; 7(4):319327. doi: 10.1370/afm.996

[8] Andersen HE, Eriksen K, Brown A. Follow-up services for stroke survivors after hospital discharge - A randomized control study. ClinRehabil 2002; 16:593-603. doi:10.1191/ $0269215502 \mathrm{cr} 528 \mathrm{oa}$

[9] Harrington R, Taylor G, Hollinghurst S, Reed M, Kay H, Wood VA. A community-based exercise and education scheme for stroke survivors: A randomized controlled trial and economic evaluation. ClinRehabil 2010; 24:315. doi:10.1177/0269215509347437

[10] Strupeit S, Wolf-Ostermann K, Buss A, Dassen $\mathrm{T}$. Effectiveness of a nursing consultation intervention for older people with functional mobility impairments: a prospective, longitudinal study. JNR 2013 (accepted May 18 2013).

[11] Neller K. Kooperation und Verweigerung: Eine Non - Response - Studie. In: Zuma Nachrichten 2005; 57:9-36.

Citation: Steve Strupeit, Arne Buss. Response Rates in a Nursing Intervention Longitudinal Study on Vulnerable Elderly Patients, ARC Journal of Nursing and Healthcare. 2017; 3(4): 22-26. doi: dx.doi.org/ 10.20431/2455-4324.0304005.

Copyright: (C) 2017 Authors. This is an open-access article distributed under the terms of the Creative Commons Attribution License, which permits unrestricted use, distribution, and reproduction in any medium, provided the original author and source are credited. 